\title{
Hybrid energy storage system optimal sizing for urban electrical bus regarding battery thermal behavior
}

\author{
Si Mohamed Faresse, Mohamed Assini, Abdallah Saad \\ Laboratory of Electrical Systems and Energy, National Higher School of Electricity and Mechanics (ENSEM), \\ Hassan II University of Casablanca, Morocco
}

\begin{tabular}{l} 
Article Info \\
\hline Article history: \\
Received April 19, 2019 \\
Revised Dec 31, 2019 \\
Accepted Jan 8, 2020 \\
\hline
\end{tabular}

Keywords:

Battery

Battery thermal behavior

Buck-boost DC/DC converter

Fully electrical bus

Hybrid energy storage system

Supercapacitor

\begin{abstract}
This paper proposes an algorithm for sizing the hybrid energy storage system of an urban electrical bus regarding battery thermal behavior. The aim of this study is to get the supercapacitors optimal contribution part in the hybrid energy storage system to keep the battery temperature within its allowable limit. A semi-active parallel topology that uses supercapacitors as a main source of energy is considered. According to the bus mechanical parameters and the ARTEMIS driving cycle, the power and energy demand are calculated. Using mathematical models for the battery, supercapacitors and DC-DC converter, several simulations are performed for different hybridization percentages. While observing the evolution of battery temperature, the most favorable hybridization percentage is defined.
\end{abstract}

Copyright $₫ 2020$ Institute of Advanced Engineering and Science. All rights reserved.

\section{Corresponding Author:}

Si Mohamed Faresse,

Laboratory of Electrical Systems and Energy,

Department of Electrical Engineering,

National Higher School of Electricity and Mechanics,

Hassan II University of Casablanca,

El Jadida Road, km 7, Casablanca, Morocco.

Email: sm.faresse@gmail.com

\section{NOMENCLATURE}

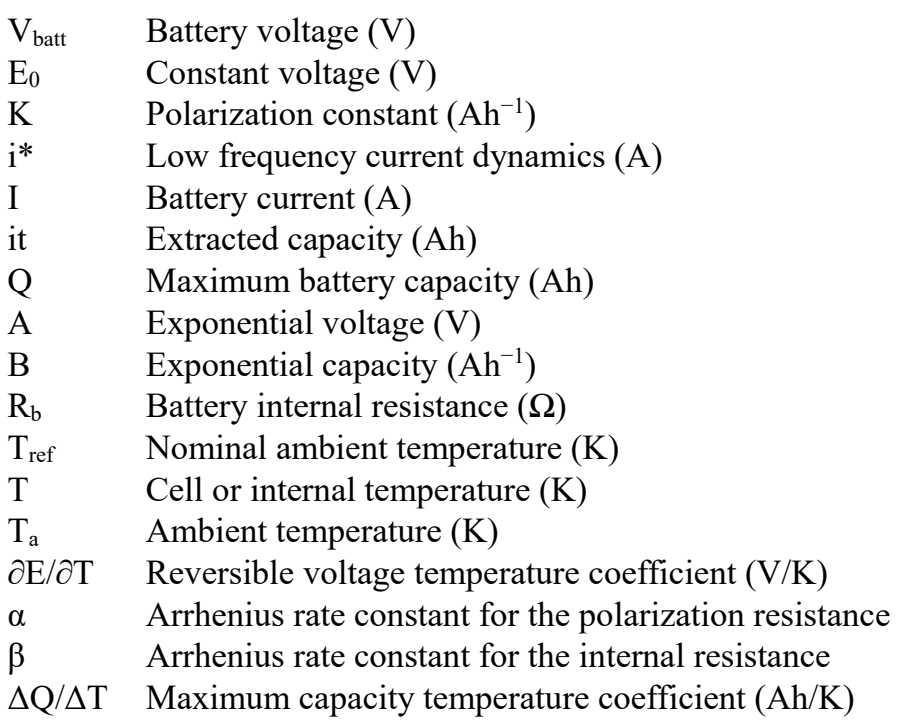




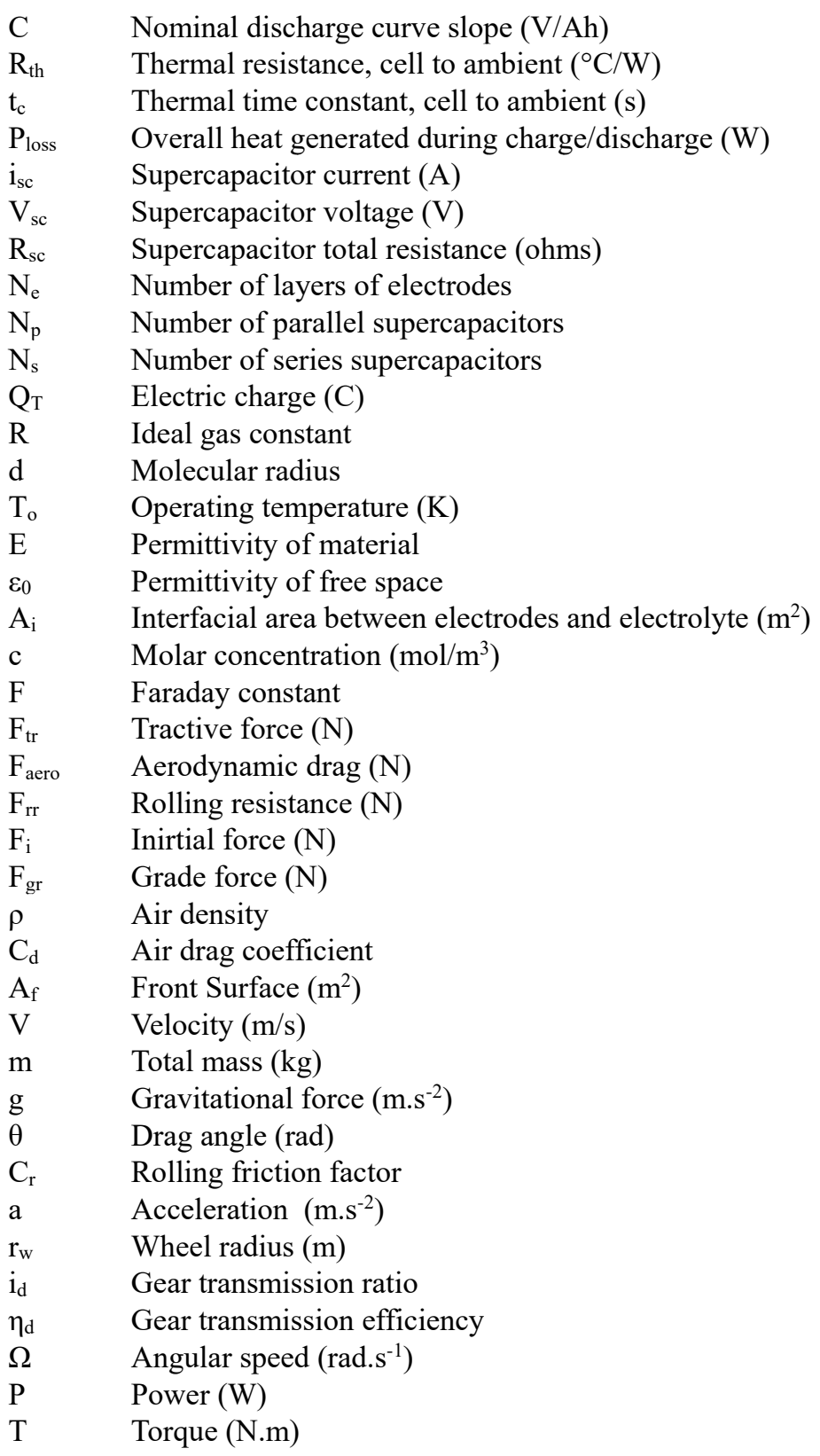

\section{INTRODUCTION}

The first autonomous electric buses were equipped with batteries as a source of energy [1]. These batteries have some disadvantages, namely a too slow dynamic [2] and overheating problem [3,4]. The combination of batteries and supercapacitors (SC) is the suitable solution for electric vehicle [5]. This combination has complementary qualities and provides an excellent solution that can increase dynamic behavior and cover a wide range of power and energy requirements and it was demonstrated that this combination has lower battery costs [6], a general increase in battery life and higher overall system efficiency [7]. Starting from the observation that battery buses are used almost exclusively in urban areas rather than for long-distance transport. The urban transport has relatively short intervals between recharging possibilities. Externally based energy storage on SC can be a solution since they can charge much faster than conventional batteries [8].

In the literature, most of the reported works focus solely on the electrical behavior of hybrid energy storage system (HESS). While the behavior of the battery temperature in this kind of application has not yet been treated. All HESS sizing methodologies for electric buses do not considerate the battery temperature evolution. And to remedy to this problem, supercapacitors oversizing is done.

Obviously, HESS topologies are very diverse, depending mainly on the type of application [9]. For the studied case, the selected topology will use the SC as the main source [10]. Our study is to redo this dimensioning while considering the temperature of the battery to choose the optimal capacity value of 
supercapacitors. In this study, an algorithm is proposed to define the minimum SC energy part in the hybrid storage system for electrical bus to maintain the battery in its permissible temperature zone. In this work we neglected the regenerative braking energy. The suggested algorithm is applied to "Irizar ie" bus, with a total mass of $16000 \mathrm{~kg}$ following an ARTEMIS driving cycle on a working day of 24 round trips. Total energy required is calculated. Then, capacity part of each element is defined and for each percentage of hybridization the temperature evolution is determined using battery model which consider temperature effect.

This paper is organized as follows: After the Introduction is given in the first section, the System Description and Modeling are introduced in section 2. The Research Method is presented in section 3. Then, the Electric Bus Energy Storage Sizing is addressed in section 4. Finally, section Simulation Results develops battery thermal behavior for different percentage of hybridization. The conclusions are given in the last section.

\section{DESCRIPTION AND SYSTEM MODELING}

\subsection{Hybrid energy storage system topologies}

Four possible topologies $[11,12,13]$ for the HESS are presented below:

\subsubsection{Parallel passive topology}

The basic passive parallel hybrid configuration is shown in Figure 1, the SC pack and the batteries are directly connected in parallel to the load. Because of the direct connection, the SC pack basically acts as a low-pass filter. The main advantage is the ease of implementation and no complicated control device required. The disadvantage of this configuration is that the power sharing between the battery and the SC pack is uncontrolled and dictated solely by the parasitic elements. Also the DC bus voltage is not regulated and varies depending on the voltage range of the batteries, which influences the design load.

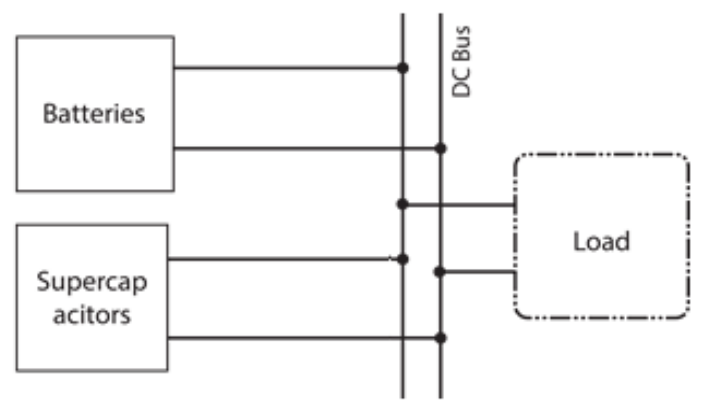

Figure 1. Passive parallel hybrid configuration

\subsubsection{Parallel active topology}

The multi-converter configuration uses two separate bidirectional back-boost converters as shown in Figure 2. The batteries and SC pack voltage can be kept lower than the DC bus voltage, less balancing problems. The voltage of the SC pack can vary in a wide range so that the capacitor is fully used. The advantage of this configuration is that the power of the batteries and SC pack can be individually controlled according to their state of charge and power requirements. The disadvantage of this topology is the increase in the number of components and the cost.

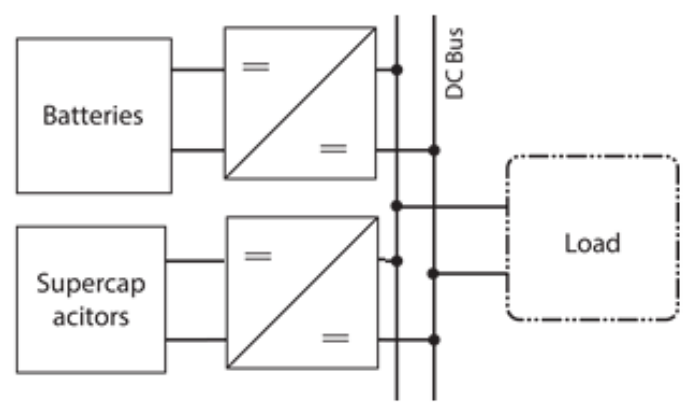

Figure 2. Active parallel hybrid configuration 


\subsubsection{Parallel semi active battery/supercapacitor topology}

The Parallel Semi Active battery/supercapacitor configuration is illustrated in Figure 3. In this configuration, the batteries voltage can be kept lower or higher than the SC pack voltage. The SC pack is connected to the DC bus and works directly as a low-pass filter. But the power of the batteries is uncontrollable. The control strategy applied to this topology allows the DC link voltage to vary in a range so that SC pack energy can be used more efficiently.

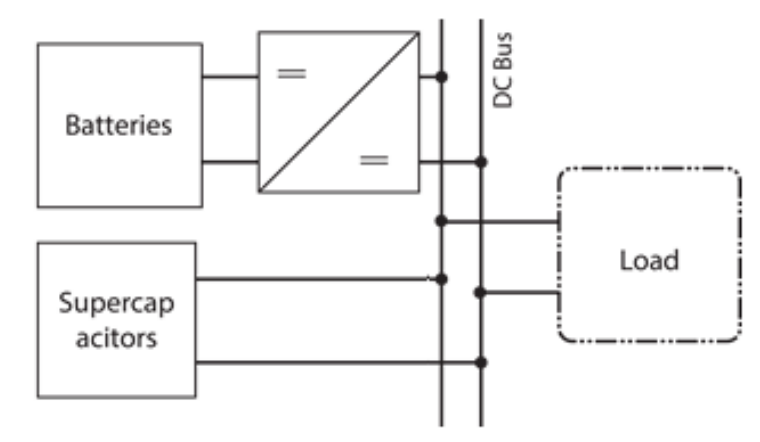

Figure 3. Battery/Supercapacitor parallel configuration

\subsubsection{Parallel semi active supercapacitor/battery topology}

Figure 4 shows the diagram of the HESS configuration using a bi-directional buck-boost converter for the SC pack interface, the SC pack voltage can be used in a wider range. This configuration has a single controlled power source. However, the bidirectional converter must be oversized to handle the power of the SC pack. In addition, the nominal voltage of the SC pack may be lower. The batteries are connected directly to the DC bus. Therefore, the DC bus voltage is fixed.

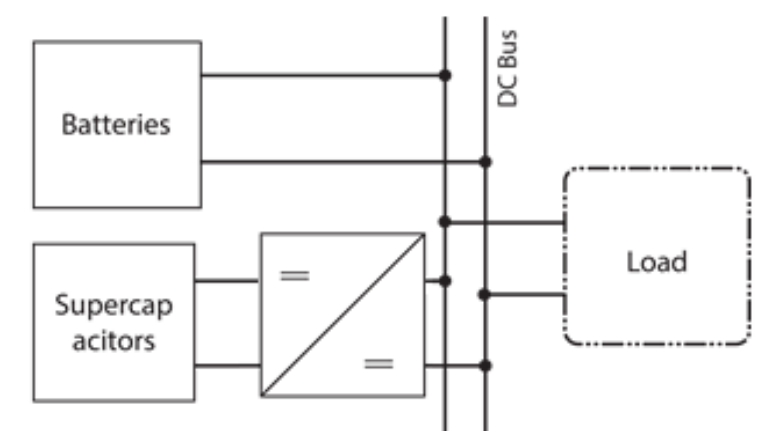

Figure 4. Supercapacitor/battery parallel configuration

\subsection{Electric bus system description}

Our goal is to use SC pack as the main power source for the bus because of their power density and their dynamic, which will be recharged at each bus stop to solve the problem of their low energy density. The battery will intervene in case of the SC discharge. The proper configuration is the Parallel Active Topology. It allows the maximum use of stored energy in SC while keeping the nominal voltage of the load. Due to its cost, the parallel active configuration will be discarded. Due to its advantages [14] the Parallel Semi Active Supercapacitor/Battery Topology will be used in the bus, where the overall system is shown in Figure $5[15,16]$.

The supercapacitor (SC1) that can produce and absorb peak power is the main element of the energy storage system of the electric urban bus, which can be charged by the other SC in the bus stop. The battery will be used in extreme conditions when the supercapacitor is almost exhausted. The general structure of the charging station at the bus stop [17] is illustrated in Figure 6. The electric urban bus SC can be charged by (SC2) supercapacitor through a DC/DC converter at each bus stop when passengers get on and off. SC2 can be charged by the power grid via an AC/DC converter between them with a lower power density before the next bus arrives. With this method, the impact of surge on the power distribution network can be avoided. 


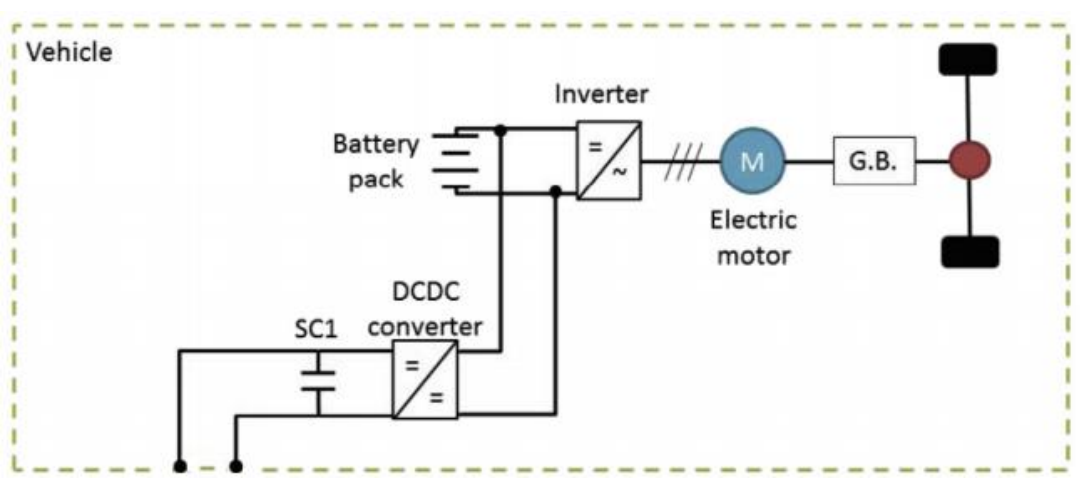

Figure 5. Scheme of electric bus storage system

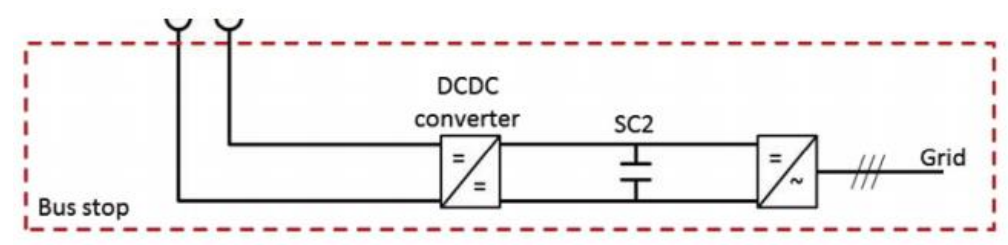

Figure 6. Scheme of electric bus powertrain

\subsection{Hybrid energy storage system modeling}

\subsubsection{Battery model}

In this work, we use MATLAB model for lithium-ion battery. Two models will be presented below (with and without temperature effect). For each model the discharge equation will be presented. The lithium-ion battery model without temperature effect is given as [18]:

$$
V_{\text {batt }}\left(\text { it }, i^{*}, i\right)=E_{0}-K \frac{Q}{Q-i t} \cdot i^{*}-K \frac{Q}{Q-i t} \cdot i t+A \cdot \exp (-B \cdot i t)-R_{b} \cdot i
$$

The impact of temperature on the model parameters is represented bellow [19]

$$
\mathrm{V}_{\text {batt }}\left(\text { it , } \mathrm{i}^{*}, \mathrm{i}, \mathrm{T}, \mathrm{T}_{\mathrm{a}}=\mathrm{E}_{0}(\mathrm{~T})-\mathrm{K}(\mathrm{T}) \frac{\mathrm{Q}\left(\mathrm{T}_{\mathrm{a}}\right)}{\mathrm{Q}\left(\mathrm{T}_{\mathrm{a}}\right)-\mathrm{it}} \cdot\left(\mathrm{i}^{*}+\mathrm{it}\right)+\mathrm{A} \cdot \exp (-\mathrm{B} . \mathrm{it})-\mathrm{C} \cdot \mathrm{it}+\mathrm{R}_{\mathrm{b}}(\mathrm{T}) \cdot \mathrm{i}\right.
$$

with:

$$
\begin{aligned}
& \mathrm{E}_{0}(\mathrm{~T})=\left.\mathrm{E}_{0}\right|_{\mathrm{T}_{\text {ref }}}+\frac{\partial \mathrm{E}}{\partial \mathrm{T}}\left(\mathrm{T}-\mathrm{T}_{\text {ref }}\right) \\
& \mathrm{K}(\mathrm{T})=\left.\mathrm{K}\right|_{\mathrm{T}_{\mathrm{ref}}} \cdot \exp \left(\alpha \cdot\left(\frac{1}{\mathrm{~T}}-\frac{1}{\mathrm{~T}_{\mathrm{ref}}}\right)\right. \\
& \mathrm{Q}\left(\mathrm{T}_{\mathrm{a}}\right)=\left.\mathrm{Q}\right|_{\mathrm{T}_{\mathrm{a}}}+\frac{\Delta \mathrm{Q}}{\Delta \mathrm{T}}\left(\mathrm{T}_{\mathrm{a}}-\mathrm{T}_{\mathrm{ref}}\right) \\
& \mathrm{R}_{\mathrm{b}}(\mathrm{T})=\left.\mathrm{R}_{\mathrm{b}}\right|_{\mathrm{T}_{\text {ref }}} \cdot \exp \left(\beta \cdot\left(\frac{1}{\mathrm{~T}}-\frac{1}{\mathrm{~T}_{\mathrm{ref}}}\right)\right.
\end{aligned}
$$

The cell or internal temperature $\mathrm{T}$, at any given time $\mathrm{t}$, is expressed as:

$$
\mathrm{T}(\mathrm{t})=L^{-1}\left(\frac{P_{\text {loss }} R_{t h}+T_{a}}{1+s \cdot t_{\mathrm{c}}}\right)
$$


where:

$$
\mathrm{P}_{\text {loss }}=\left(\mathrm{E}_{0}(T)-V_{\text {batt }}(\mathrm{T})\right) \cdot \mathrm{i}+\frac{\partial \mathrm{E}}{\partial \mathrm{T}} \cdot \mathrm{i} \cdot \mathrm{T}
$$

\subsubsection{Supercapacitor model}

The SC is an emerging technology in the field of energy storage systems. Energy storage is performed by the means of static charge rather than of an electro-chemical process that is inherent to the battery [20]. The supercapacitor model used in this work is a generic MATLAB model parameterized to represent most popular types of SC [21]. The SC output voltage is expressed using a Stern equation as:

$$
\mathrm{V}_{s c}=\frac{N_{s} Q_{T} d}{N_{p} N_{e} \varepsilon \varepsilon_{0} A_{i}}+\frac{2 N_{e} N_{s} R T_{o}}{F} \sinh ^{-1}\left(\frac{Q_{T}}{N_{p} N_{e}^{2} A_{i} \sqrt{8 R T_{o} \varepsilon \varepsilon_{0} c}}\right)-R_{s c} \cdot i_{s c}
$$

With : $Q_{T}=\int i_{s c} d t$

\subsubsection{DC/DC converter model}

DC/DC converters can be represented by two types of models, namely the switching models and the average value models. Switching models are mainly used for design purposes and to study the types of pulse width modulated systems with respect to switching harmonics and losses. These models require a low sampling time to observe all the switching actions, which makes the simulation very long.

On the contrary, medium-valued models take less time because the switches are replaced by controlled voltage/current sources. The switching harmonics are not represented, but all the dynamics of the converter are maintained, which makes these models attractive, because a longer sampling time can be used. Models of DC/DC converters of average value are used in this paper, as shown in Figure 7. The design of the control loops is performed taking into account the dynamics of the model [22].

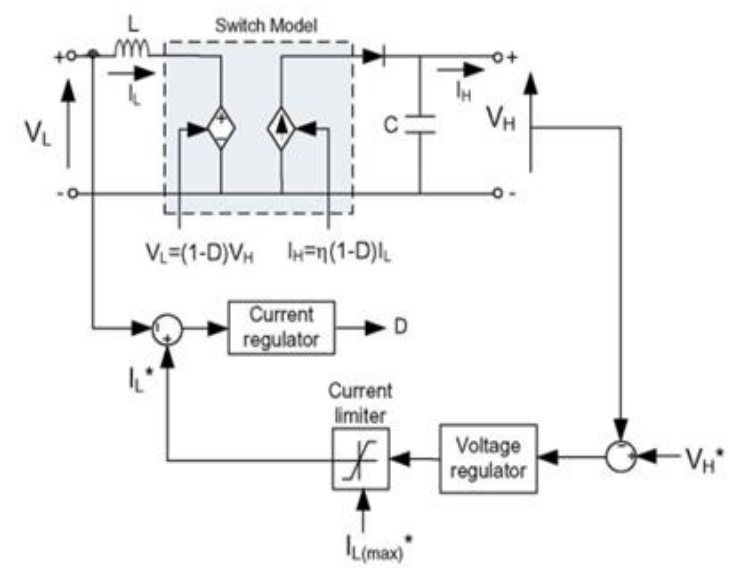

(a)

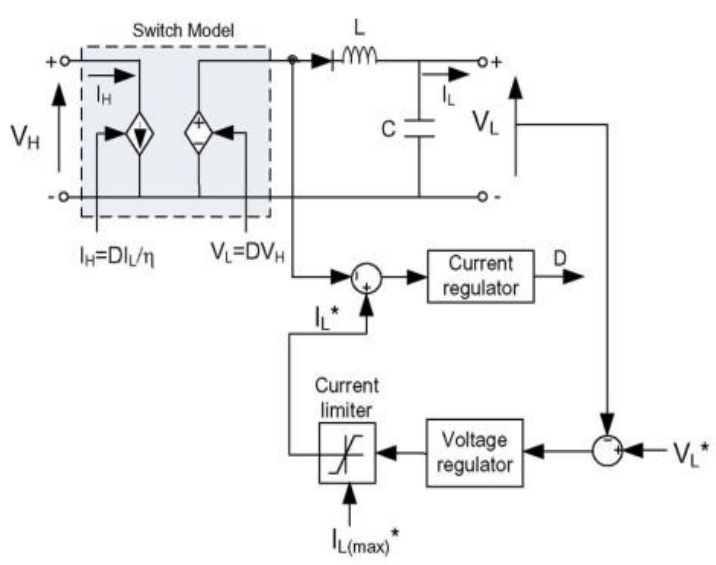

(b)

Figure 7. DC/DC Converter Model, (a) Boost type. (b) Buck type

\section{RESEARCH METHOD}

In this article, the choice of the hybrid energy storage system elements for a totally electric bus is carried out according to the diagram represented in Figure 8. The illustrated approach consists in determining all the energies consumed between two consecutive stops on the total path of the bus. These energies are normally determined from the mechanical characteristics of the bus and the bus driving cycle. Then choose a supercapacitor pack to ensure the minimum of calculated energies. Next, determine the battery capacity to ensure the power supply of the bus during a working day, knowing that the supercapacitors pack, which will be recharged at each bus stop, will provide partial or total power between two consecutive stops. 
Subsequently, use the model developed under MATLAB/Simulink, which uses the parallel semiactive topology Supercapacitor/Battery, with the model of the battery which considers the temperature effect, by applying the chosen value of the supercapacitors and battery. Then observe the evolution of the battery temperature during a day of operation. If the observed temperature exceeds the battery permissible value, the energy value just above the energy used for the supercapacitor must be chosen from the energies already calculated. And repeat the same algorithm until finding the optimum value of HESS elements.

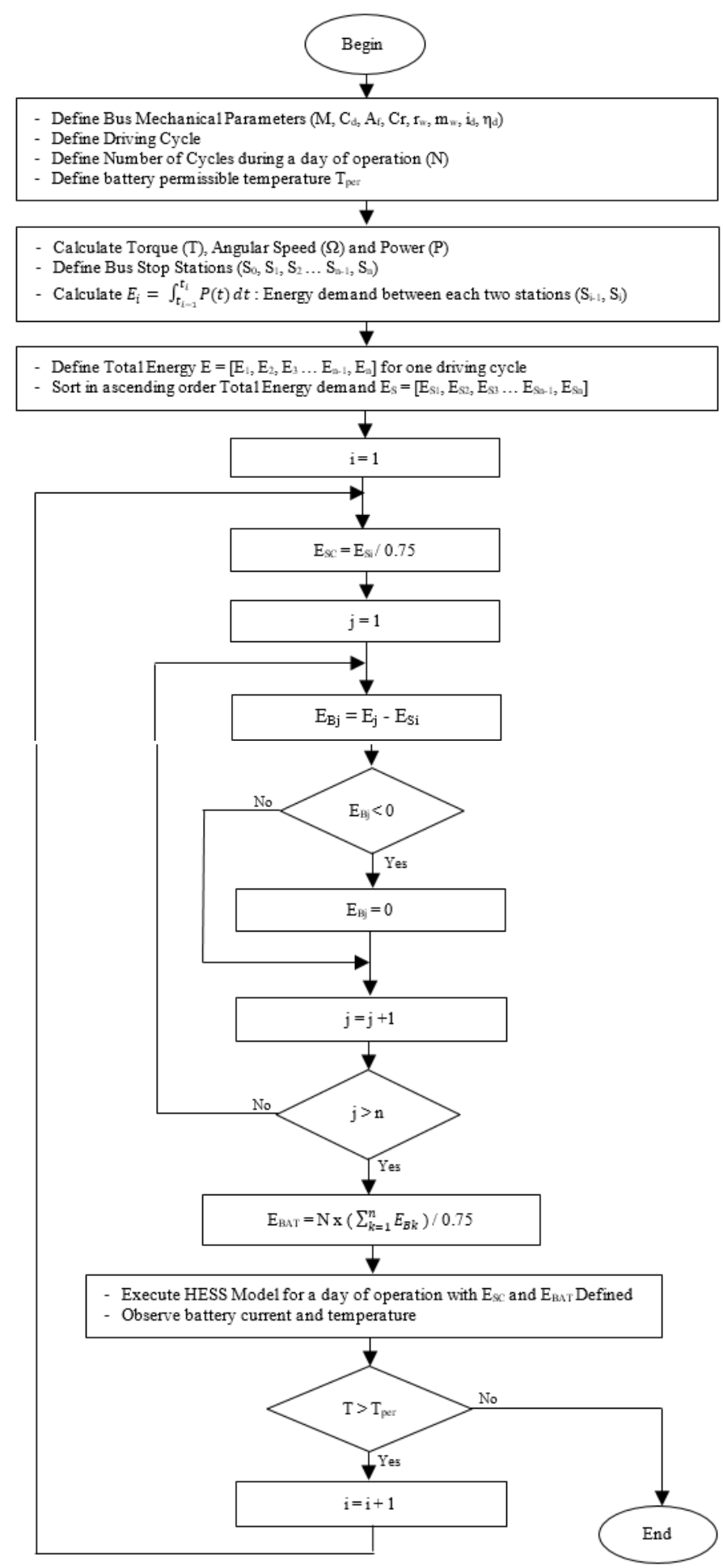

Figure 8. Flow chart of the proposed algorithm 


\section{ELECTRIC BUS ENERGY STORAGE SIZING}

The objective of this part is to size the energy storage system of a fully electrical bus from well-defined specifications.

\subsection{Bus mechanical parameters}

The main mechanical characteristics of the chosen bus are summarized in Table 1. The vehicle is constructed applying the body of "Irizar ie" bus with a new rear transmission ratio of 8.

Table 1. Bus mechanical parameters

\begin{tabular}{lcc}
\hline Parameters & Symbol & Values \\
\hline Total mass (fully loaded) & $\mathrm{M}$ & $16000 \mathrm{~kg}$ \\
Air drag coefficient & $\mathrm{C}_{\mathrm{d}}$ & 0.65 \\
Front surface & $\mathrm{A}_{\mathrm{f}}$ & $8 \mathrm{~m}^{2}$ \\
Rolling friction factor & $\mathrm{C}_{\mathrm{r}}$ & 0.008 \\
Wheel radius & $\mathrm{r}_{\mathrm{w}}$ & $0.48 \mathrm{~m}$ \\
Wheel mass & $\mathrm{m}_{\mathrm{w}}$ & $50 \mathrm{~kg}$ \\
Gear transmission ratio & $\mathrm{i}_{\mathrm{d}}$ & $8: 1$ \\
Gear transmission efficiency & $\eta_{\mathrm{d}}$ & 0.97 \\
\hline
\end{tabular}

\subsection{Driving cycle}

The chosen driving cycle is ARTEMIS Urban [23] illustrated in Figure 9.

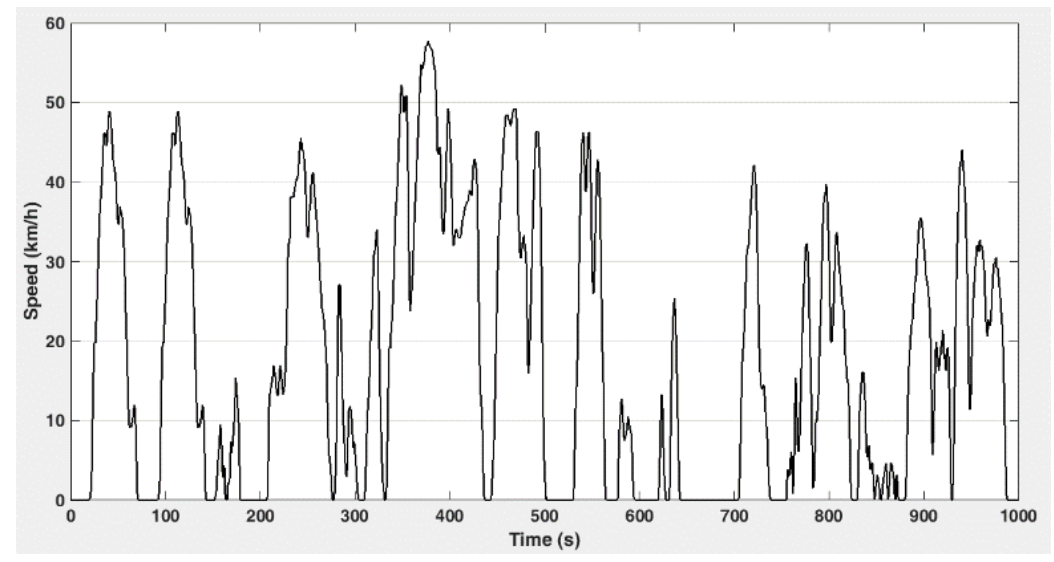

Figure 9. ARTEMIS urban driving cycle

The main features of this cycle are:
Distance
: $4870 \mathrm{~m}$
Duration
: $993 \mathrm{sec}$
Average speed : $17.6 \mathrm{~km} / \mathrm{h}$
Maximum speed : $57.7 \mathrm{~km} / \mathrm{h}$

\subsection{Motor torque, angular speed and power calculation}

The rotational speed and power demand for the powertrain and the torque demand to overcome friction forces (rolling and air resistance) are depicted in Figure 10.

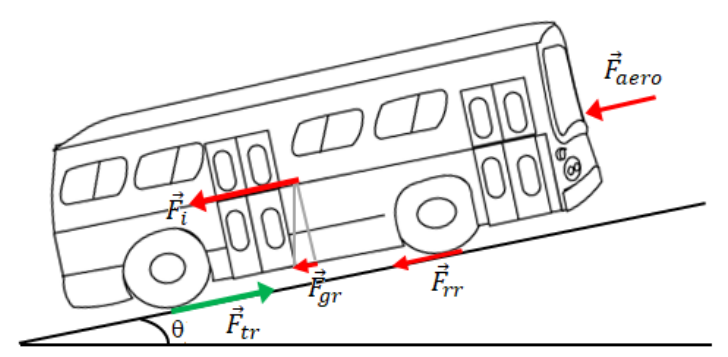

Figure 10. Forces applied to the bus 
The bus traction force required is given by this equation [24-26]:

$$
F_{\mathrm{tr}}=F_{\text {aero }}+F_{\mathrm{rr}}+F_{\mathrm{i}}+F_{\mathrm{gr}}
$$

where:

$$
\begin{aligned}
& F_{\text {aero }}=1 / 2 \rho C_{d} A_{f} V^{2} \\
& F_{\text {rr }}=\mathrm{mg} \sin (\theta) \\
& F_{g r}=\mathrm{mg} C_{r} \\
& F_{\mathrm{i}}=\mathrm{a} m_{i} \\
& m_{i}=1.04 m \\
& \mathrm{a}=\frac{F_{\mathrm{tr}}-\left(F_{\text {aero }}+F_{\mathrm{rr}}+F_{\mathrm{gr}}\right)}{m_{i}}
\end{aligned}
$$
Power:

From the tractive force and the linear velocity, we can deduce the motor torque, angular velocity and

$$
\begin{aligned}
& T=\frac{F_{t r} r_{w}}{i_{d} \eta_{d}} \\
& \Omega=\frac{v i_{d}}{r_{w}} \\
& P=T . \Omega
\end{aligned}
$$

Figures 11, 12, and 13 show respectively the calculated torque, angular velocity and power required for an ARTEMIS driving cycle.

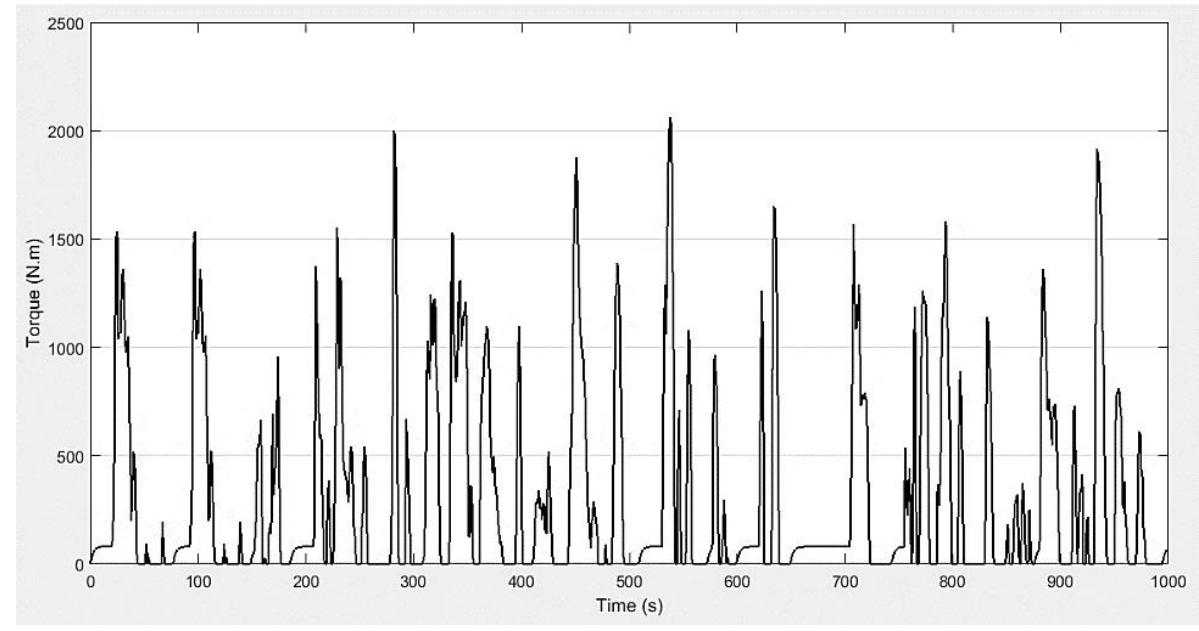

Figure 11. Bus motor torque 


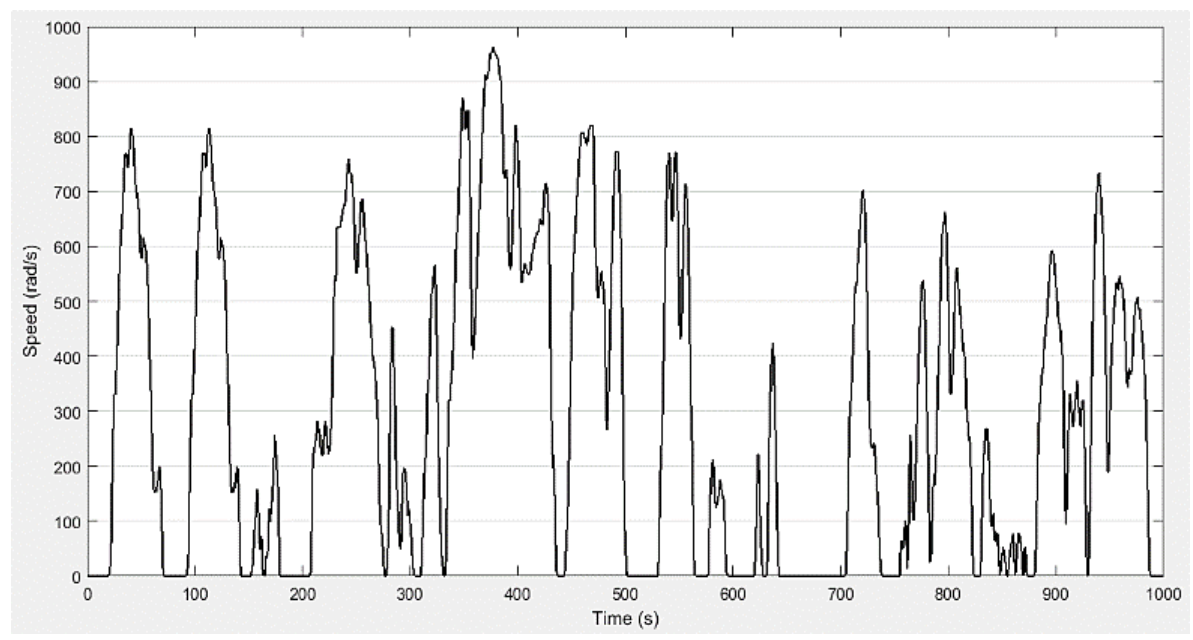

Figure 12. Bus motor angular velocity

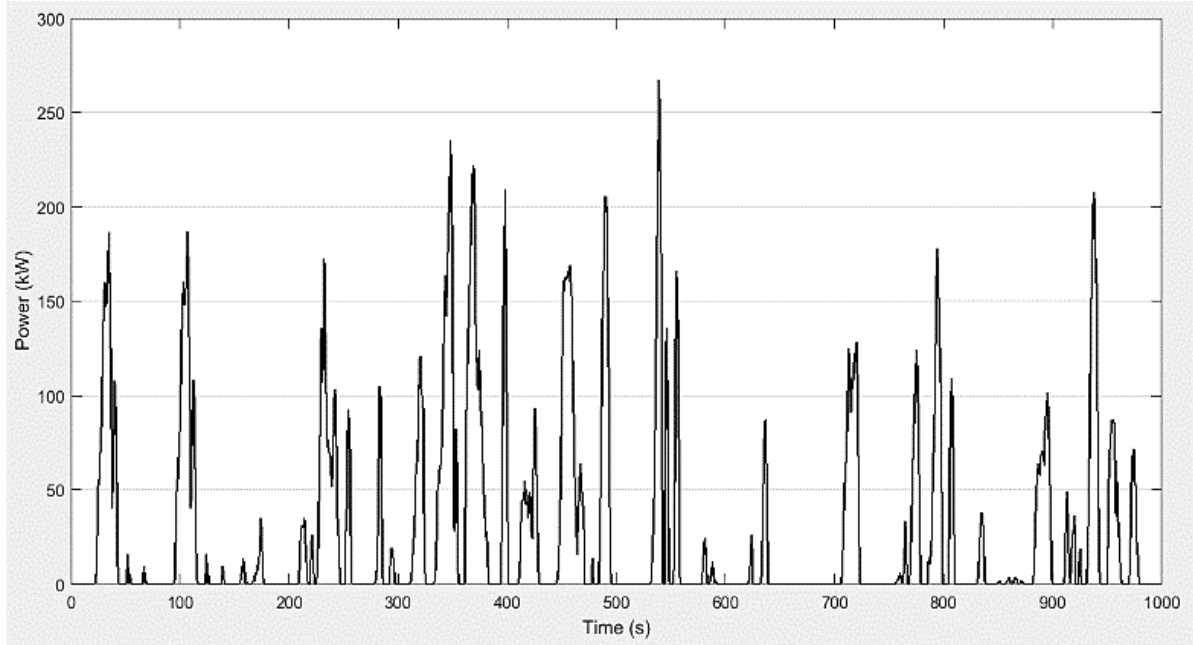

Figure 13. Bus motor power

\subsection{Bus energy autonomous calculation}

We define eight stations in the given driving cycle, the total driving range is $4870 \mathrm{~m}$. The duration and the demand energy between two successive stations are calculated and listed in Table 2. The total energy demand for 1000 seconds ARTEMIS driving cycle is approximately $7.6 \mathrm{kWh}$. We estimate that the route between two bus terminals is two ARTEMIS cycles followed by a 15 minute break (each trip will last 2900 seconds). For a day operation, we define 24 round trips or 48 ARTEMIS cycles. The total energy required for a day is $364 \mathrm{kWh}$.

Table 2. Energy consumption between two successive bus stops

\begin{tabular}{cccc}
\hline Bus stop N $^{\circ}$ & Duration $(\mathrm{s})$ & Energy $(\mathrm{Wh})$ \\
\hline 1 & 0 & $\rightarrow 72$ & 559 \\
2 & 73 & $\rightarrow 180$ & 604 \\
3 & $181 \rightarrow 503$ & 3617 \\
4 & $504 \rightarrow 566$ & 616 \\
5 & $567 \rightarrow 596$ & 25 \\
6 & 597 & $\rightarrow 644$ & 100 \\
7 & 645 & $\rightarrow 739$ & 383 \\
8 & 740 & $\rightarrow 989$ & 1686 \\
\hline
\end{tabular}




\section{SIMULATION RESULTS}

All simulation tests are executed with different operating conditions in MATLAB/Simulink environment. The simulations have been carried out during $69600 \mathrm{~s}$ which represent the bus day operation time. In this study, we proposed eight simulation tests that represent the battery temperature evolution for each HESS combination given by Table 3. The aim is to find the best configuration with minimum SC capacity, to ensure the autonomous and the battery permissible temperature. The chosen battery parameters are summarized in Table 4. For each simulation performed, we present the battery current draw between two bus terminals that lasts about 2000 seconds followed by 900 seconds rest. The evolution of the temperature corresponding to this current draw during a day of operation are presented respectively in Figures 14-20 for different HESS combinations given by Table 3.

Table 3. HESS combinations

\begin{tabular}{ccccc}
\hline Case $\mathrm{N}^{\circ}$ & SC capacity $(\mathrm{F})$ & SC energy $(\mathrm{Wh})$ & Battery energy $(\mathrm{kWh})$ & Battery energy (Ah) \\
\hline 1 & 0 & 0 & 485 & 871 \\
2 & 4 & 34 & 472 & 848 \\
3 & 16 & 133 & 439 & 788 \\
4 & 60 & 511 & 330 & 592 \\
5 & 86 & 744 & 274 & 492 \\
6 & 93 & 802 & 262 & 470 \\
7 & 146 & 1264 & 217 & 389 \\
8 & 259 & 2248 & 124 & 222 \\
9 & 556 & 4823 & 0 & 0 \\
\hline
\end{tabular}

Table 4. Battery parameters

\begin{tabular}{lc}
\hline Parameter & Value \\
\hline Type & Lithium-ion \\
Nominal Voltage (V) & 557 \\
Initial State of Charge (\%) & 100 \\
Battery Response Time (s) & 30 \\
Cut-off Voltage (V) & 378 \\
Fully Charged Voltage & 587 \\
Internal Resistance (Ohms) & 0.00504 \\
Initial cell temperature (deg. C) & 20 \\
Nominal ambient temperature T1 (deg. C) & 20 \\
Thermal resistance, cell-to-ambient (deg. C/W) & 0.4 \\
Thermal time constant, cell-to-ambient (s) & 20000 \\
\hline
\end{tabular}

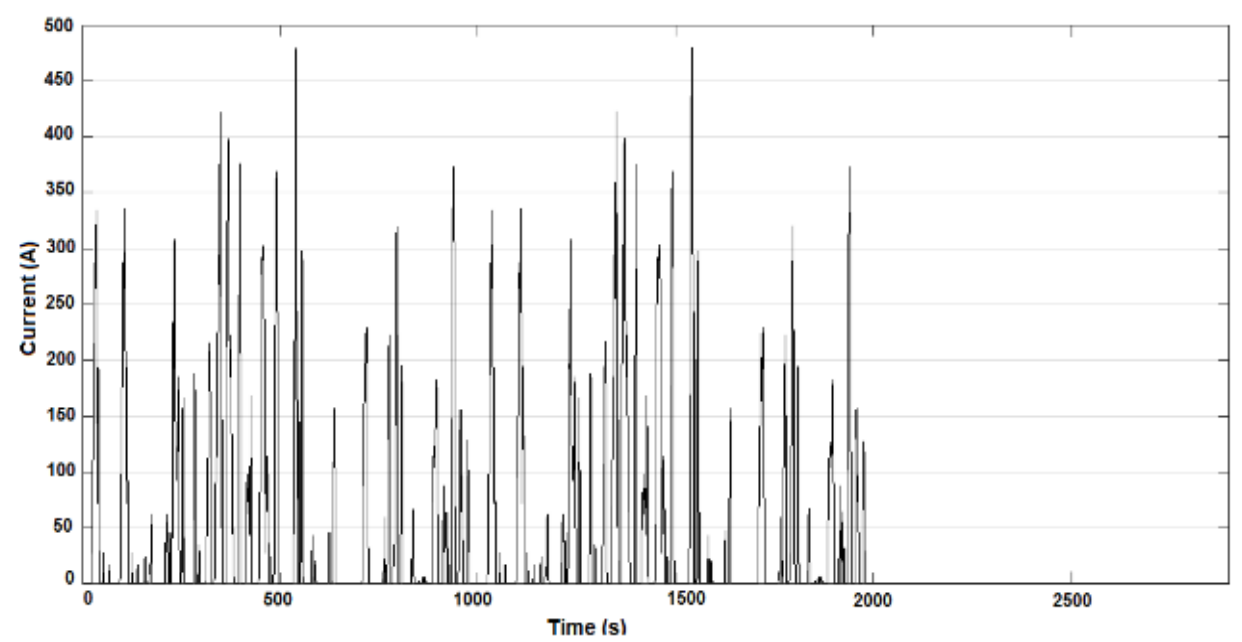

(a)

Figure 14. (a) Battery current 


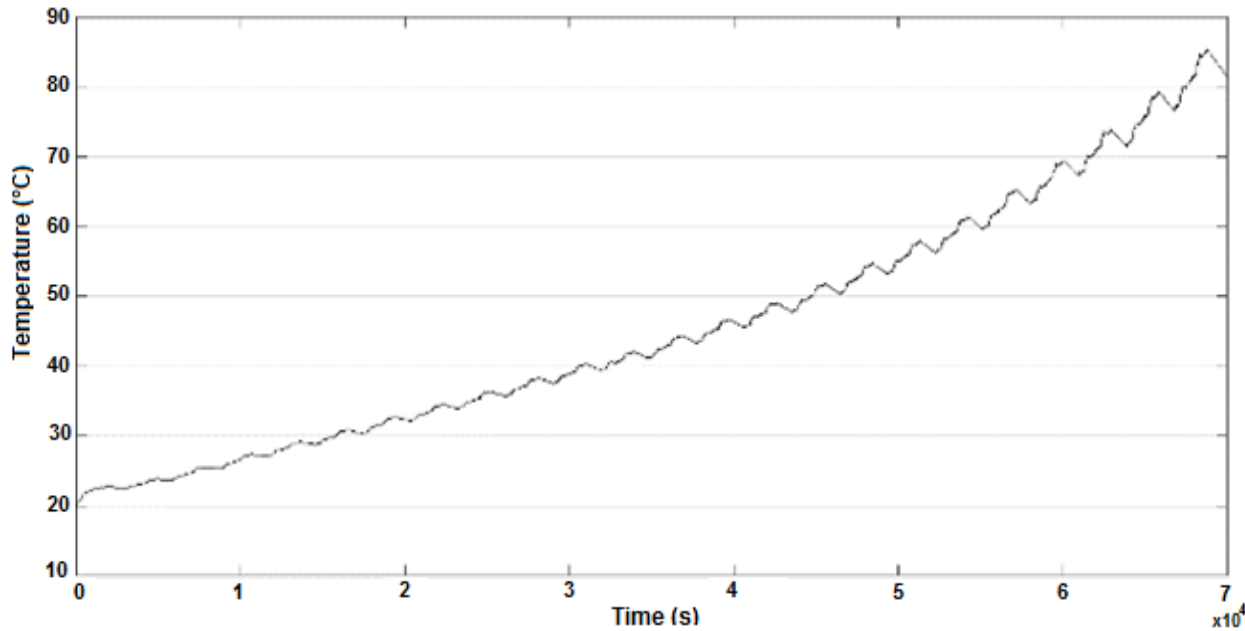

(b)

Figure 14. (b) Battery temperature, $\left(\mathrm{E}_{\mathrm{Batt}}=871 \mathrm{Ah}\right.$ and $\left.\mathrm{E}_{\mathrm{SC}}=0 \mathrm{Wh}\right)($ continue $)$

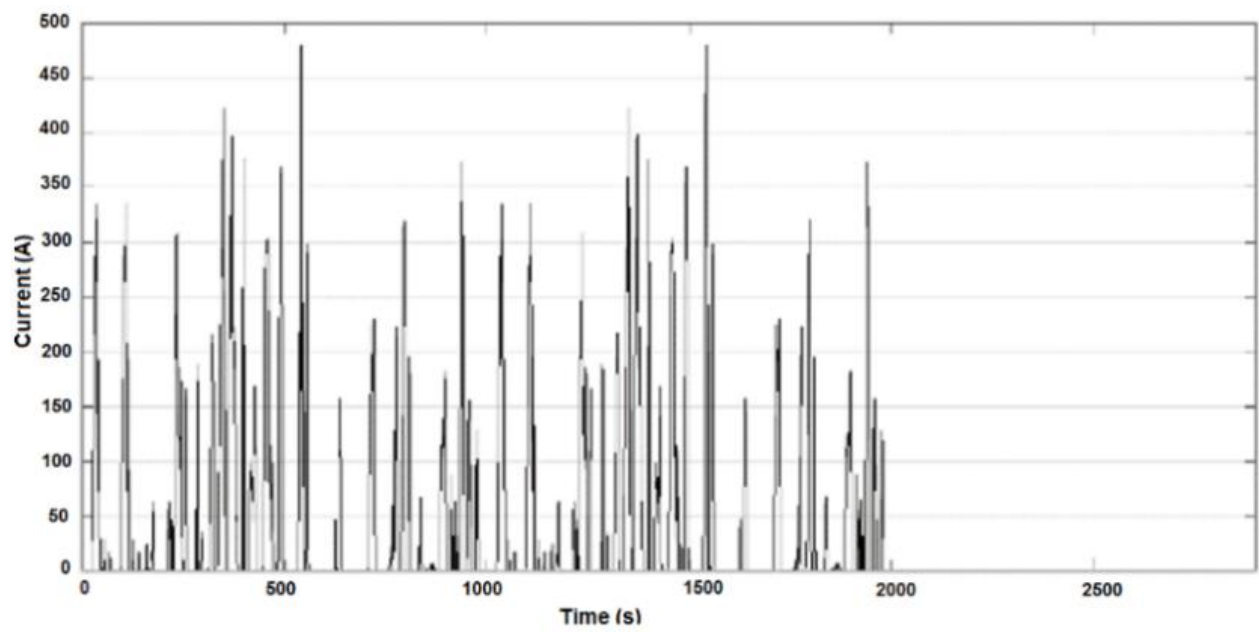

(a)

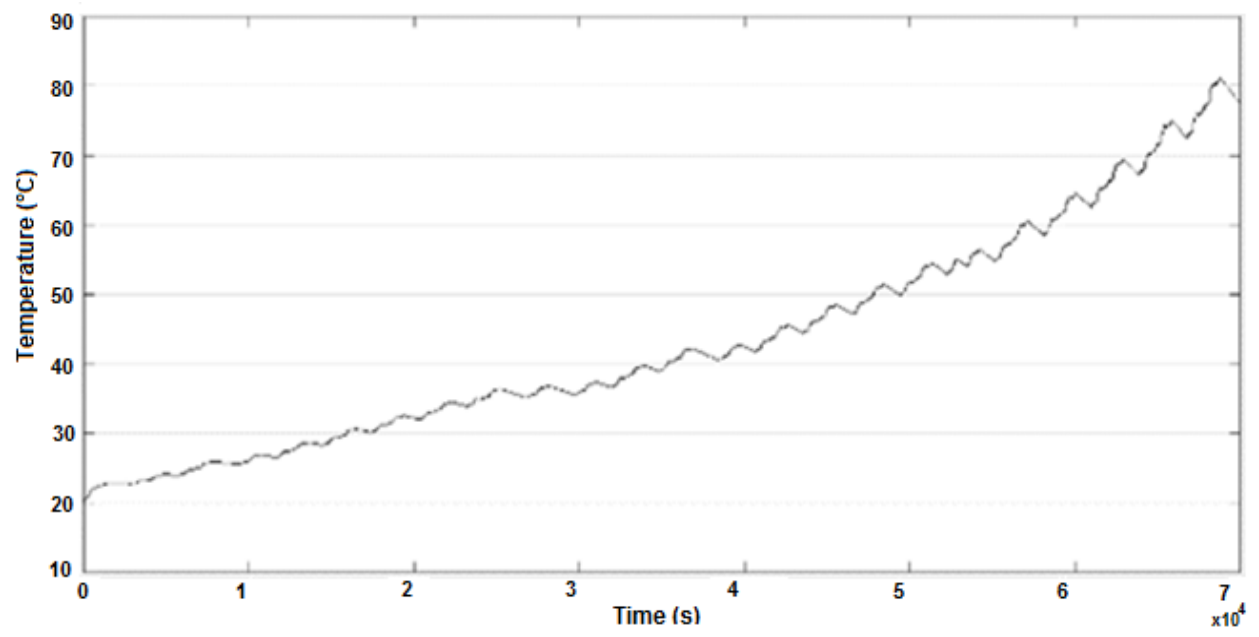

(b)

Figure 15. (a) Battery current, (b) Battery temperature, $\left(E_{B a t t}=848 \mathrm{Ah}\right.$ and $\left.E_{S C}=34 \mathrm{Wh}\right)$ 


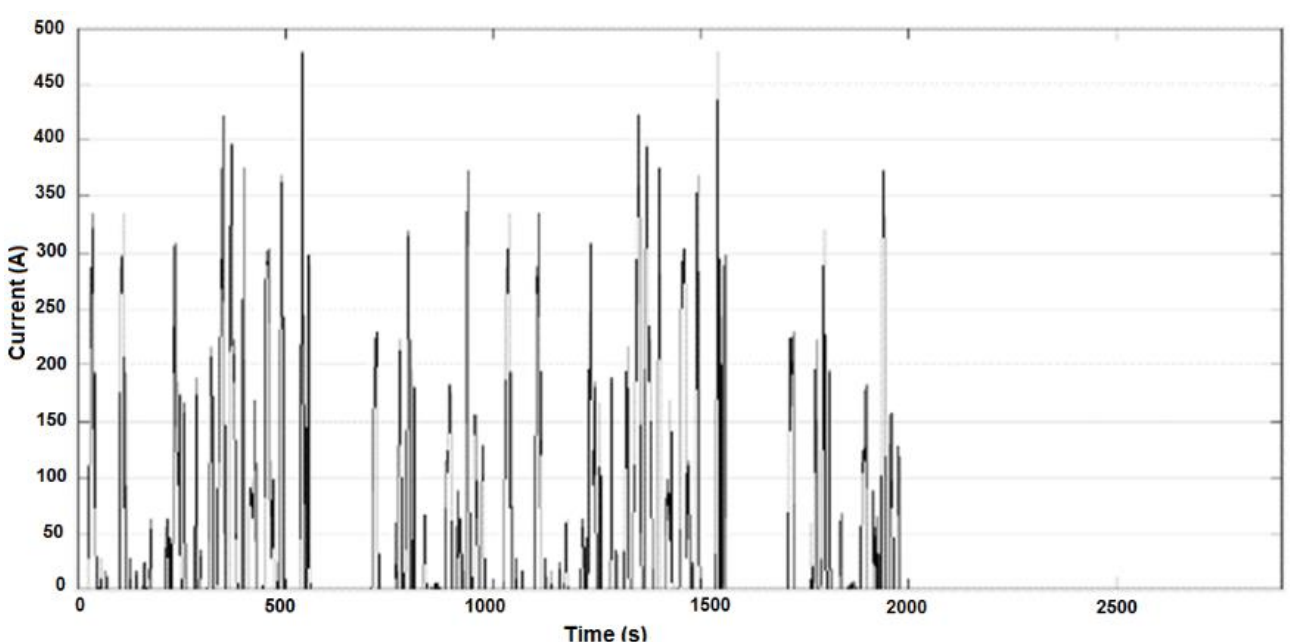

(a)

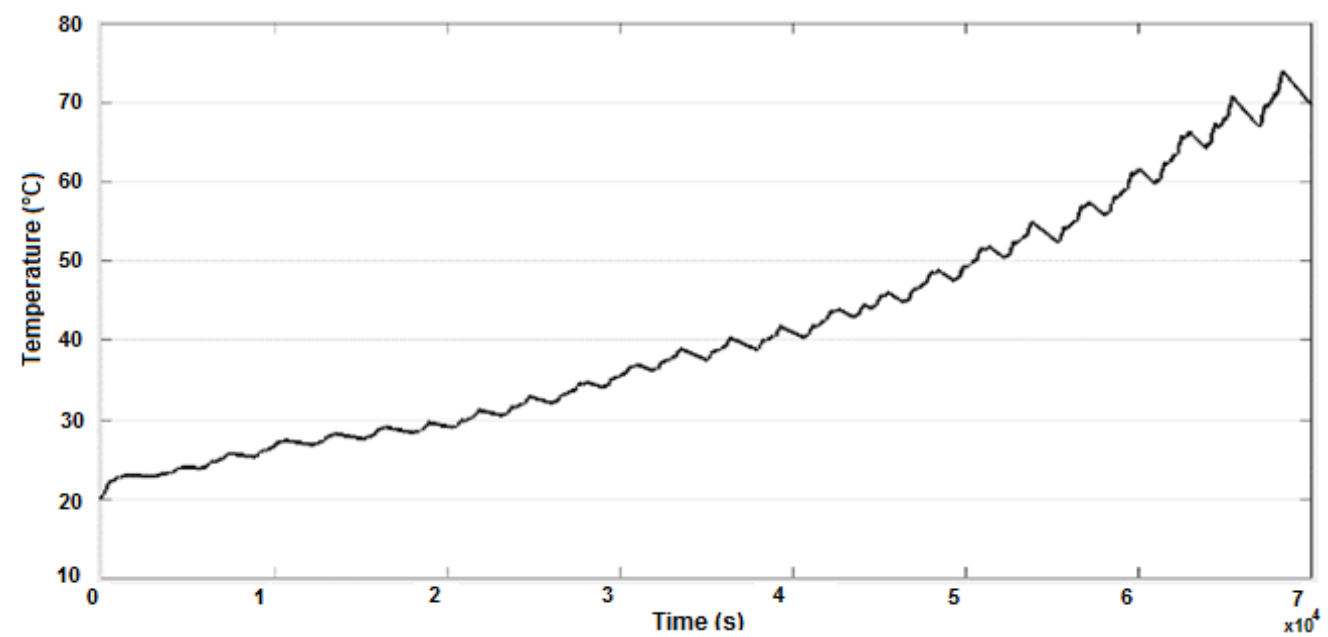

(b)

Figure 16. Battery current (a) and Battery temperature (b) $\left(\mathrm{E}_{\mathrm{Batt}}=788 \mathrm{Ah}\right.$ and $\left.\mathrm{E}_{\mathrm{SC}}=133 \mathrm{Wh}\right)$

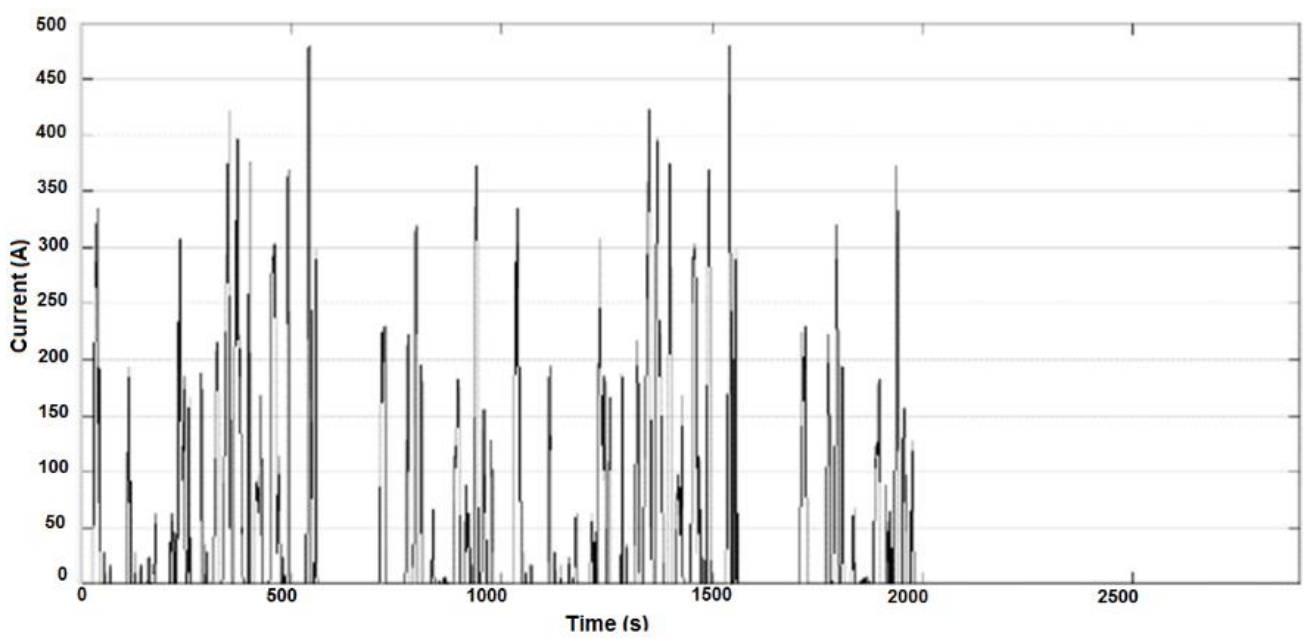

(a)

Figure 17. Battery current (a) Battery temperature 


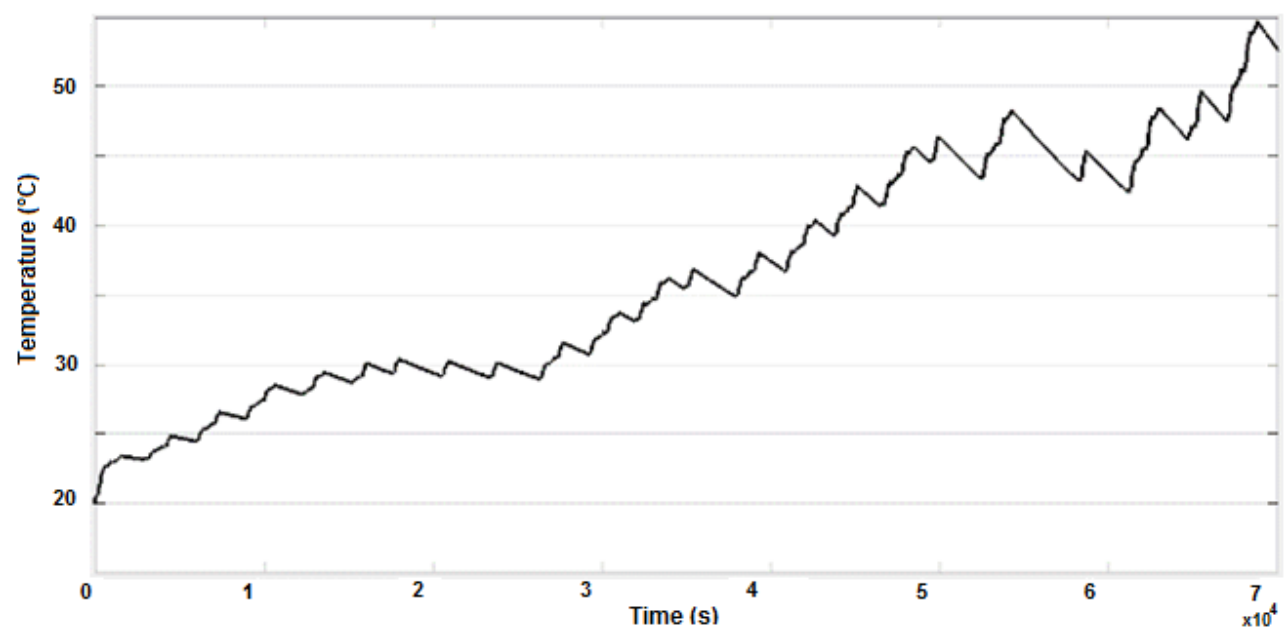

(b)

Figure 17 . Battery current $(\mathrm{b})\left(\mathrm{E}_{\mathrm{Batt}}=592 \mathrm{Ah}\right.$ and $\left.\mathrm{E}_{\mathrm{SC}}=511 \mathrm{Wh}\right)($ continue $)$

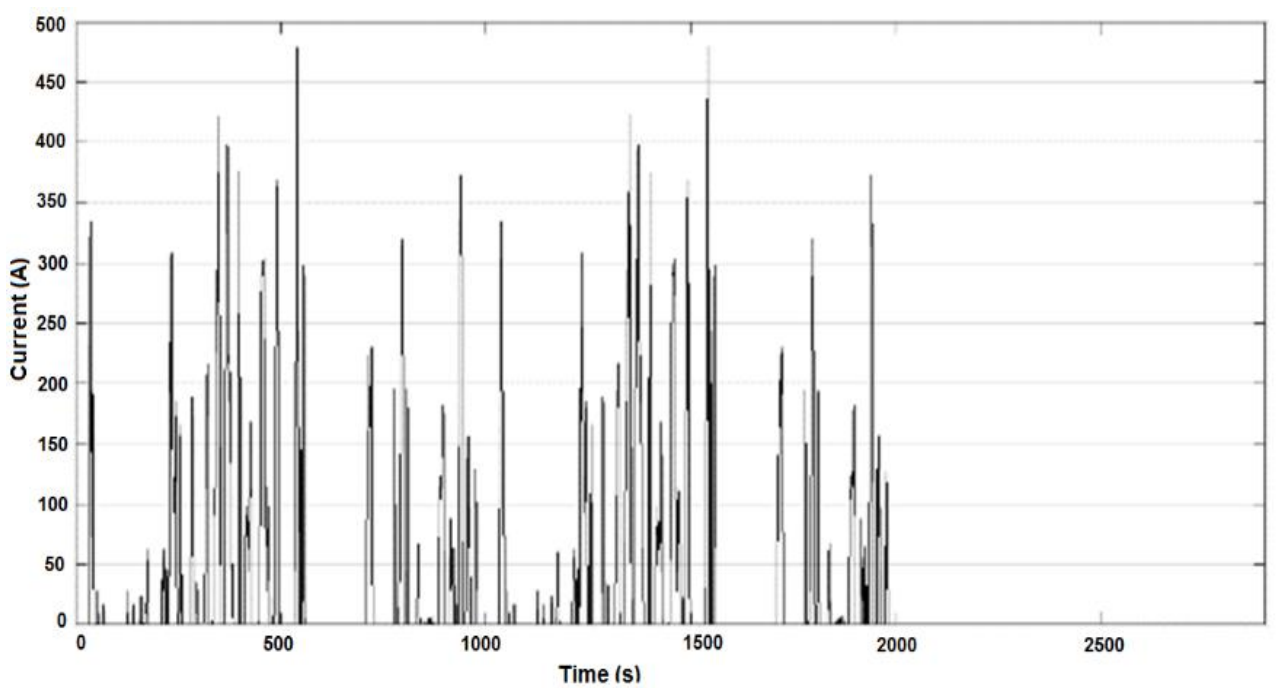

(a)

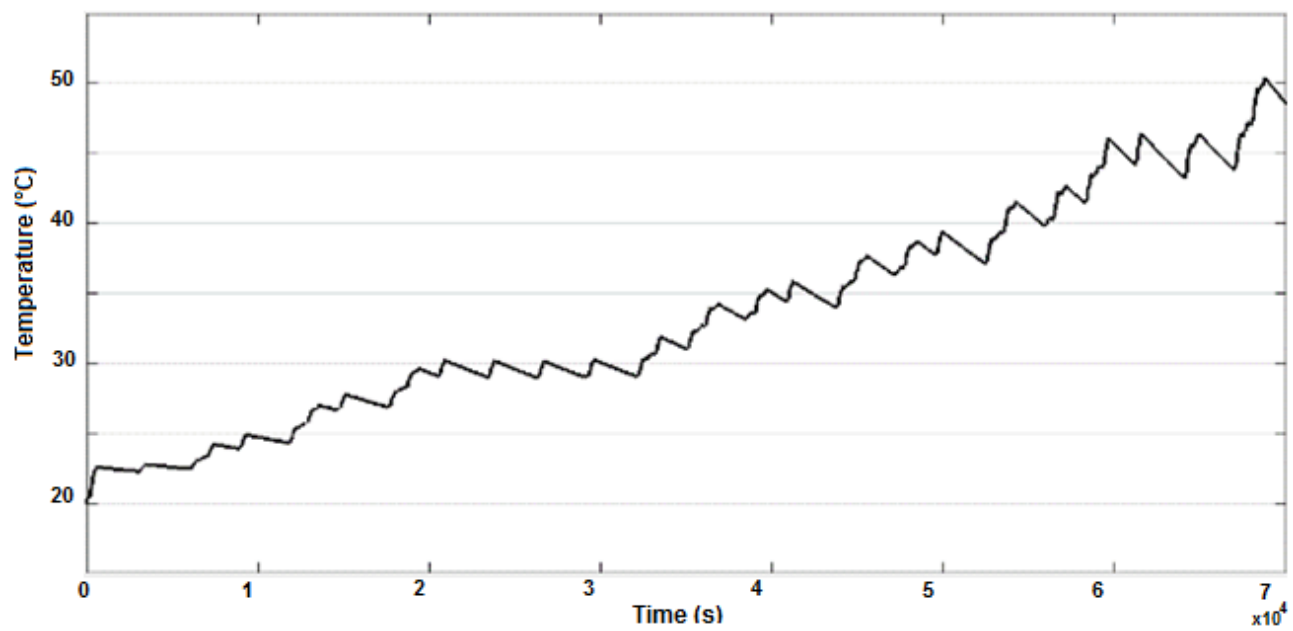

(b)

Figure 18. Battery current (a) and Battery temperature (b) $\left(E_{\text {Batt }}=492 \mathrm{Ah}\right.$ and $\left.\mathrm{E}_{\mathrm{SC}}=744 \mathrm{Wh}\right)$ 


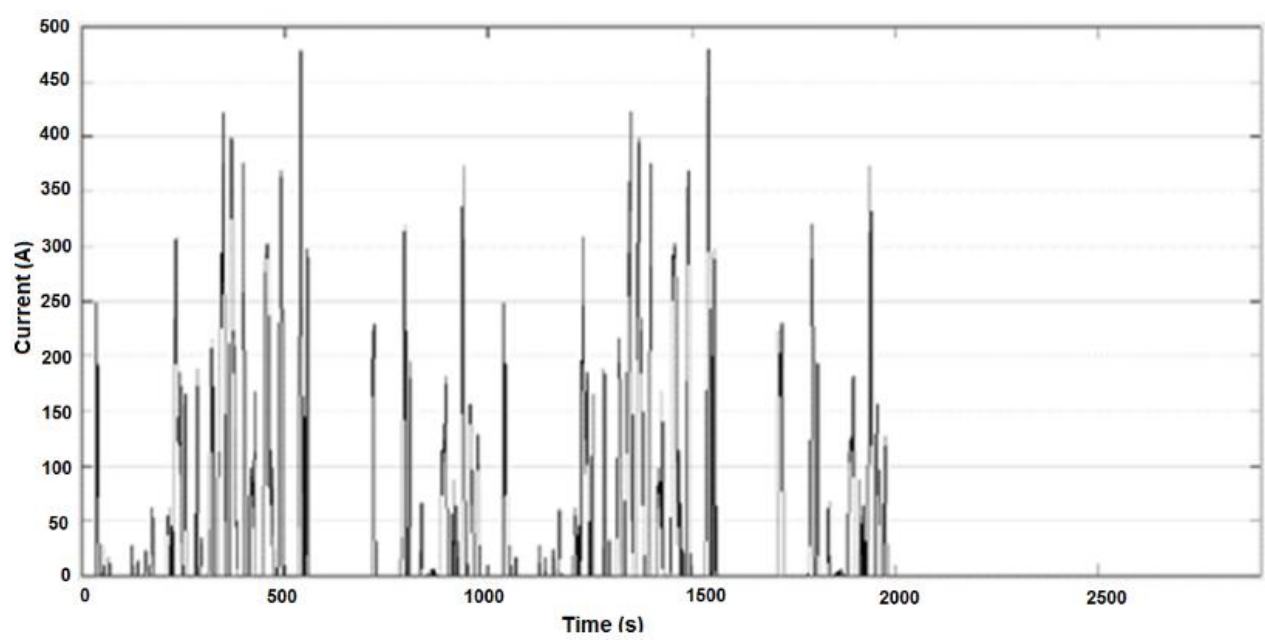

(a)

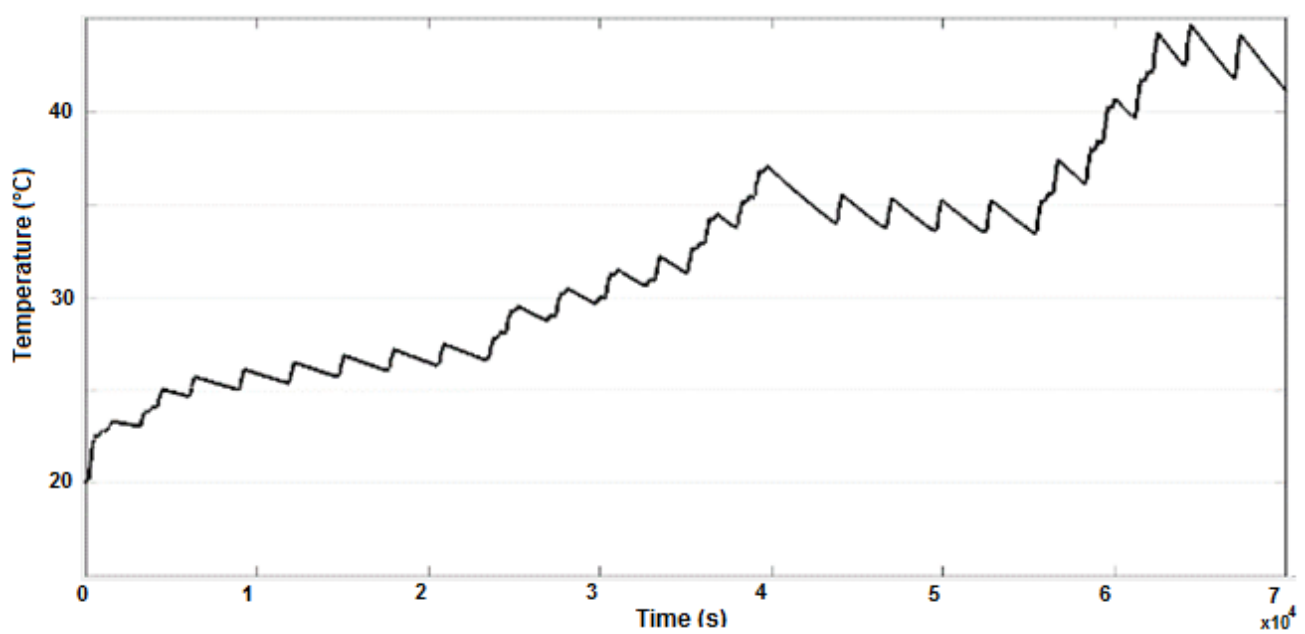

(b)

Figure 19. Battery current (a) and Battery temperature (b) $\left(E_{B a t t}=470 \mathrm{Ah}\right.$ and $\left.E_{S C}=802 \mathrm{Wh}\right)$

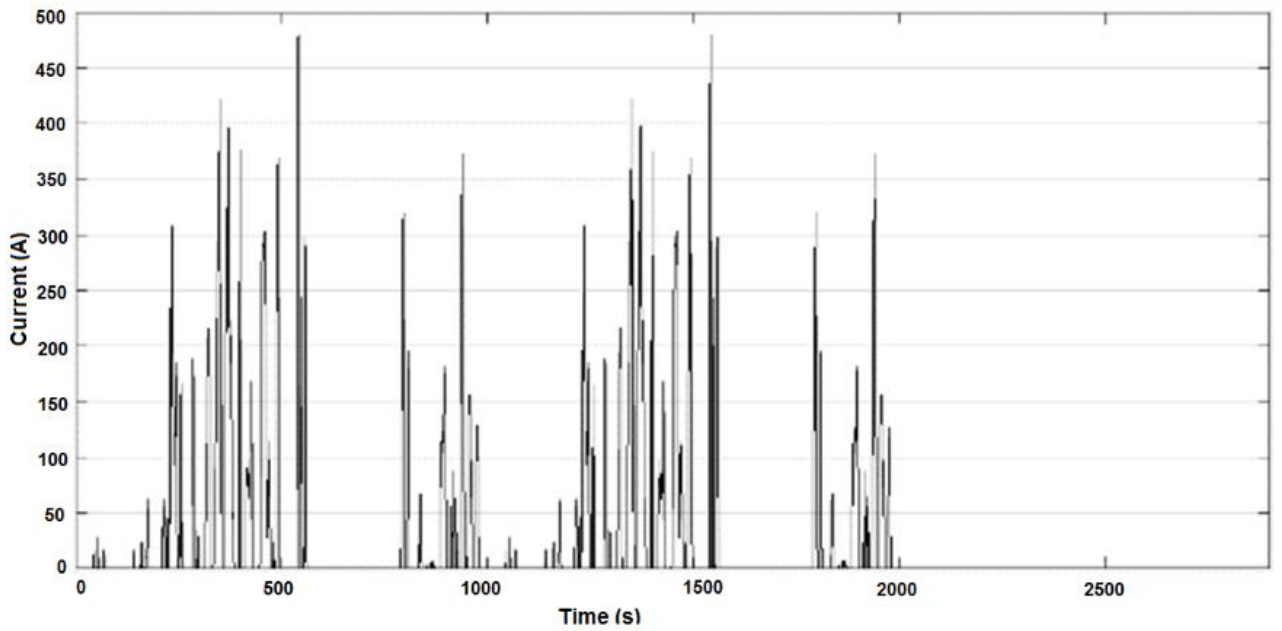

(a)

Figure 20. Battery current (a) Battery temperature 


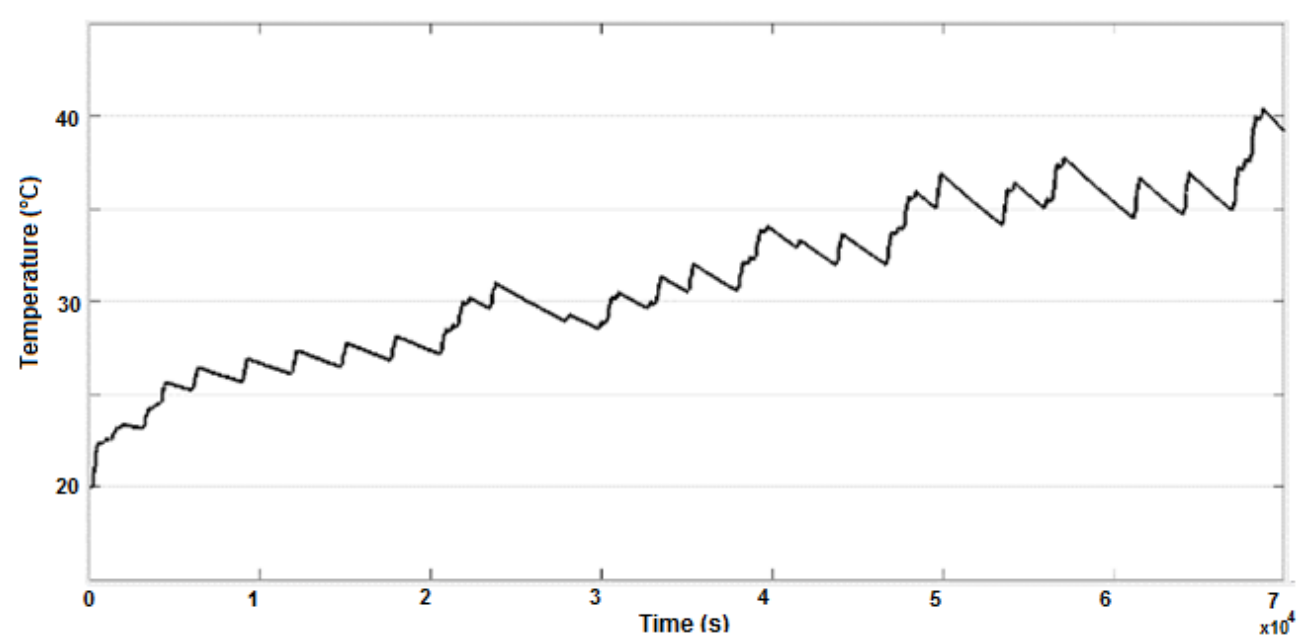

(b)

Figure 20. Battery current $(\mathrm{b})\left(\mathrm{E}_{\mathrm{Batt}}=389 \mathrm{Ah}\right.$ and $\left.\mathrm{E}_{\mathrm{SC}}=1264 \mathrm{Wh}\right)($ continue $)$

The following Table 5 summarizes the results of the simulations performed. We note that from a capacity of $60 \mathrm{~F}$ we can keep the battery temperature within the allowable limits. For 60F Capacity, the maximum temperature reached is $55^{\circ} \mathrm{C}$ which is below the battery permissible temperature $\left(60^{\circ} \mathrm{C}\right)$. $\mathrm{SC}$ energy is about $511 \mathrm{Wh}$ which is $0.16 \%$ of the battery energy $(330 \mathrm{kWh})$. With this percentage of hybridization, the battery capacity has been reduced by $32 \%$.

Table 5. Maximum temperature reached for each combination

\begin{tabular}{ccccc}
\hline $\mathrm{C}(\mathrm{F})$ & $\mathrm{ESC}_{\text {SC }}(\mathrm{Wh})$ & $\mathrm{E}_{\text {Batt }}(\mathrm{kWh})$ & $\mathrm{E}_{\text {Batt }} / \mathrm{E}(\%)$ & $\mathrm{T}\left({ }^{\circ} \mathrm{C}\right)$ \\
\hline 0 & 0 & 485 & 100 & 85 \\
4 & 34 & 472 & 97 & 80 \\
16 & 133 & 439 & 91 & 74 \\
60 & 511 & 330 & 68 & 55 \\
86 & 744 & 274 & 56 & 50 \\
93 & 802 & 262 & 54 & 45 \\
146 & 1264 & 217 & 45 & 40 \\
\hline
\end{tabular}

\section{CONCLUSION}

Based on the ARTEMIS driving cycle and the mechanical parameters of the bus, we calculated the power required for its training system, then we calculated the energy required for its operation during a day. We have determined the optimal share of the energy to be stored in the supercapacitors, to allow the battery to operate in its zone of admissible temperature. The chosen bus case study with a power of 270 $\mathrm{kW}$, requires a daily energy autonomy of $364 \mathrm{kWh}$ is the equivalent of $871 \mathrm{Ah}$ battery under $557 \mathrm{~V}$. We have found the right combination of supercapacitors and batteries, namely $511 \mathrm{Wh}$ for supercapacitors and $592 \mathrm{Ah}$ for battery, which represents $68 \%$ of the energy required by the bus. With this combination we have limited the maximum temperature to $55^{\circ} \mathrm{C}$.

\section{ACKNOWLEDGEMENTS}

I would like to express here the very thanks to Professors: Mohamed Assini and Abdallah Saad, University Hassan II, who provided me the opportunity to do such a research in their laboratory.

\section{REFERENCES}

[1] J. Du, F. Li, J. Li, X. Wu, Z. Song, Y. Zou, and M. Ouyang, "Evaluating the technological evolution of battery electric buses: China as a case," Energy, vol. 176, no. 1, pp. 309-319, 2019.

[2] M. Soltani, J. Ronsmans, S. Kakihara, J. Jaguemont, P. Van den Bossche, J. van Mierlo, and N. Omar, "Hybrid battery/lithium-ion capacitor energy storage system for a pure electric bus for an urban transportation application," Applied Science, vol. 8, no. 7, pp. 1176-1195, 2018. 
[3] K. Jaewan, O. Jinwoo and L. Hoseong, "Review on battery thermal management system for electric vehicles," Applied Thermal Engineering, vol. 149, pp. 192-212, 2019.

[4] S. M. Faresse, M. Assini, and A. Saad, "Battery thermal behavior in hybrid energy storage unit (battery/supercapacitor) for dynamic loads," International Journal of Scientific \& Engineering Research, vol. 9, no. 2, pp. 1439-1446, 2018.

[5] L. Kouchachvili, W. Yaïci, and E. Entchev, "Hybrid battery/supercapacitor energy storage system for the electric vehicles," Journal of Power Sources, vol. 374, pp. 237-248, 2018.

[6] Z. Cabrane, M. Ouassaid, and M. Maaroufi, "Analysis and evaluation of battery-supercapacitor hybrid energy storage system for photovoltaic installation," International Journal of Hydrogen Energy, vol. 41, no. 45, pp. 20897-20907, 2016.

[7] J. Nájera, P. Moreno-Torres, M. Lafoz, R. M. de Castro, and J. R. Arribas, "Approach to hybrid energy storage systems dimensioning for urban electric buses regarding efficiency and battery aging," Energies, vol. 10, no. 11, pp. 1708-1724, 2017.

[8] W. Yusheng, H.Yongxi, X. Jiuping, and N. Barclay, "Optimal recharging scheduling for urban electric buses: A case study in Davis," Transportation Research Part E, vol. 100, pp. 115-132, 2017.

[9] R. Xiong, H. Chen, C. Wang, and F. Sun, "Towards a smarter hybrid energy storage system based on battery and ultracapacitor-a critical review on topology and energy management," Journal of Cleaner Production, vol. 202, pp. 1228-1240, 2018.

[10] S. Zhang, R. Xiong, and X. Zhou, "Comparison of the topologies for a hybrid energy-storage system of electric vehicles via a novel optimization method," SCIENCE CHINA-Technological Sciences, vol. 58, no. 7, pp. 1173-1185, 2015.

[11] T. Zimmermann, P. Keil, M. Hofmann, M. F. Horsche, S. Pichlmaier, and A. Jossen, "Review of system topologies for hybrid electrical energy storage systems," Journal of Energy Storage, vol. 8, pp. 78-90, 2016.

[12] X. Changle, W. Yanzi, H. Sideng and W. Weida, "A New Topology and Control Strategy for a Hybrid BatteryUltracapacitor Energy Storage System," Energies, vol. 7, pp. 2874-2896, 2014.

[13] S. Ziyou, L. Jianqiu, H. Xuebing, X. Liangfei, L. Languang, O. Minggao and H. Hofmann, "Multi-objective optimization of a semi-active battery/supercapacitor energy storage system for electric vehicles," Applied Energy, vol. 135, pp. 212-224, 2014.

[14] S. Ziyou, H. Hofmann, L. Jianqiu, H. Xuebing, and Z. Xiaowu, "A comparison study of different semi-active hybrid energy storage system topologies for electric vehicles," Journal of Power Sources, vol. 274, pp. 400-411, 2015 .

[15] S. Arrigoni, D. Tarsitano, and F. Cheli, "Comparison between different energy management algorithms for an urban electric bus with hybrid energy storage system based on battery and supercapacitors," Int. J. Heavy Vehicle Systems, vol. 23, no. 2, pp. 171-189, 2016.

[16] D. Tarsitano, L. Mazzola, F. Luigi Mapelli, S. Arrigoni, F. Cheli and F. Haskaraman, "On Board Energy Management Algorithm Based on Fuzzy Logic for an Urban Electric Bus with Hybrid Energy Storage System," Advanced Microsystems for Automotive Applications, pp. 179-187, 2014.

[17] Y. Huilong, D. Tarsitano, H. Xiaosong, and F. Cheli, "Real time energy management strategy for a fast charging electric urban bus powered by hybrid energy storage system," Energy, vol. 112, pp. 322-331, 2016.

[18] O. Tremblay and L. A. Dessaint, "Experimental validation of a battery dynamic model for EV applications," World Electric Vehicle Journal, vol. 3, no. 2, pp. 289-298, 2009.

[19] L. H. Saw, K. Somasundaram, Y. Ye, and A.A.O. Tay, "Electro-thermal analysis of lithium iron phosphate battery for electric vehicles," Journal of Power Sources, vol. 249, pp. 231-238, 2014.

[20] P. O. Logerais, M. A. Camara, O. Riou, A. Djellad, A. Omeiri, F. Delaleux, and J. F. Durastanti, "Modeling of a supercapacitor with a multibranch circuit," International Journal of Hydrogen Energy, vol. 40, no. 39, pp. 13725$13736,2015$.

[21] N. Xu and J. Riley, "Nonlinear analysis of a classical system: The double-layer capacitor," Electrochemistry Communications, vol. 13, no. 10, pp. 1077-1081, 2011.

[22] S. N. Motapon, L. A. Dessaint, and K. Al-Haddad, "A comparative study of energy management schemes for a fuel-cell hybrid emergency power system of more-electric aircraft," IEEE Transactions on industrial electronics, vol. 61, no. 3, pp 1320-1334, 2014.

[23] M. Andre, R. Joumard, R. Vidon, P. Tassel, and P. Perret, "Real-world European driving cycles, for measuring pollutant emissions from high- and low-powered cars," Atmospheric Environment, vol. 40, no. 31, pp. 5944-5953, 2006.

[24] W. Xiaogang, H. Weixiang, and S. Zhibin, "Research on energy management of hybrid energy storage system for electric bus," Advances in Mechanical Engineering, vol. 9, no. 10, pp. 1-13, 2017.

[25] B. Tabbache, S. Djebarri, A. Kheloui, M. Benbouzid, "A Power Presizing Methodology for Electric Vehicle Traction Motors," International Review on Modelling and Simulations, vol. 6, pp. 29-32, 2013.

[26] X. Xin and C. Zhang, "Optimal Design of Electric Vehicle Power System with the Principle of Minimum Curb Mass," Energy Procedia, vol. 105, pp. 2629 - 2634, 2017. 


\section{BIOGRAPHIES OF AUTHORS}

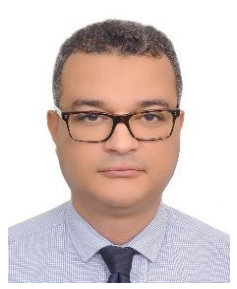

Si Mohamed Faresse is a Ph.D. student at the National Higher School of Electricity and Mechanics, Laboratory of Electrical Systems and Energy, University Hassan II of Casablanca-Morocco. His research interests include hybrid energy storage system for transport and photovoltaic applications.

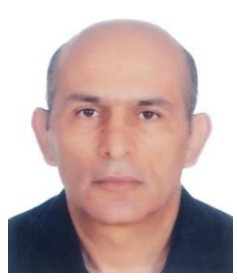

Mohamed Assini, Ph. D., Professor at the Department of Electrical Engineering, National Higher School of Electricity and Mechanics, University Hassan II of Casablanca, Morocco. His research interests include hybrid energy storage system for transport and photovoltaic applications, Renewable Energies and static converters.

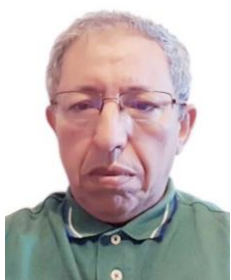

Abdallah Saad, Ph. D., Professor at the Department of Electrical Engineering, National Higher School of Electricity and Mechanics, University Hassan II of Casablanca, Morocco. His research interests include hybrid energy storage system for transport and photovoltaic applications, electricity network and Facts, Renewable Energies and smart grids. 